\title{
Smart Specialisation in Europe: Looking Beyond Regional Borders
}

\author{
Nicola Bellini*
}

\begin{abstract}
The adoption of smart specialisation involves a challenging set of novelties in the way innovation strategies are designed. One of these novelties concerns the 'outward orientation' of the innovation strategies.

In the world of open innovation and global value chains no serious innovation policy can be effective without the ability to connect local knowledge assets with knowledge existing 'elsewhere'.

In the perspective of an outward-looking smart specialisation, it would be important to be fully aware of the relational assets that individual actors (such as institutions, companies, universities, etc.) hold and that may take on a collective relevance.

Smart Specialisation simultaneously poses a triple challenge: conceptual, operational and political.
\end{abstract}

Keywords: Smart Specialisation; Global Markets; Europe; Outward Strategy

\section{Smart Specialisation: Objectives and Ambiguities}

All European Regions have been required to draft a new Regional Innovation Strategy, as ex ante condition to access the EU Structural Funds for the 2014-2020 programming period. The conditionality is also linked to the adoption of a new criterion that was proposed to inspire (and to evaluate) regional innovation policies: Smart Specialisation (Foray, Goenaga 2013). The ex-ante conditionality applies especially to the objective of the ERDF concerning research, technological development and innovation (the so-called 'thematic objective 1').

The adoption of smart specialisation involves a challenging set of novelties in the way innovation strategies are designed. Being aware of this, the EU Commission has also made available an unprecedented set of learning tools to support the processes of strategy design, including methodological guides, websites, publications, peer-review workshops, events, expert assessments etc., mostly under the umbrella of the 'S3 Platform' established at the Institute for Prospective Technological Studies in Seville ${ }^{1}$.

*Professor of Management, La Rochelle Business School (bellinin@esc-larochelle.fr)

Edited by: ISTEI - University of Milan-Bicocca

ISSN: 1593-0319

Bellini Nicola (2015) Smart Specialisation in Europe: Looking Beyond Regional Borders, Symphonya. Emerging Issues in Management (symphonya.unimib.it), n. 1, pp. 22- 29.

http://dx.doi.org/10.4468/2015.1.03bellini 
One of these novelties concerns the 'outward orientation' of the innovation strategies. According to the EU Commission, 'looking beyond regional borders' is a necessary condition in order to make the specialisation choices successful and viable. Although the process of strategy-making is far from being completed in Italy $^{2}$ and therefore a systematic survey is not yet possible, some preliminary observations, based on the on-going processes more than on final documents, are possible and are presented here. This paper also draws extensively from the author's personal experience as an expert in charge of the assessment of the S3 process in a number of regions in Italy and Spain ${ }^{3}$.

The new programming period of the EU Structural Funds (2014-2020) is not just one more round of political - bureaucratic exercises and in many respects presents itself as an historic turning point. For the first time the objective of innovation characterizes a substantial part of the available resources for regional policies. At the end of a long period of reappraisal of the fundamentals of the European Regional Policy, the traditional goal of territorial cohesion is 'welded' with the objectives of competitiveness and innovation. These two goals have been for a long time in an implicit conflict: 'cohesion' suggested the need to focus on compensatory policy to compensate for development gaps and allow convergence; 'competitiveness and innovation' seem to privilege well-focalized interventions, targeted at high-tech productions and with a built-in tendency to focus on advanced regions and metropolis.

This conflict is overcome when one departs from the traditional identification of innovation with $R \& D$ expenditures and adopts a wider view. This leads to reassess the 'necessary' spatial concentration of innovative activities and to critically reconsider the present geographical distribution of $\mathrm{R} \& \mathrm{D}$. Concentration is a fact, but also suggests the possibility of a different distribution of the innovation capacity of territories. In a policy perspective this means questioning how to exploit an innovative potential that is widely distributed among the regions of Europe, as a way to both help cohesion and increase the overall competitiveness of the Union (Bellini, Landabaso 2007). Policies are then required to re-define innovation in terms that are not shaped by a homogeneous, one-way-fits-all view based on increasing $\mathrm{R} \& \mathrm{D}$ expenditures, but according to more distinctive and differentiated patterns. "Some regions can indeed specialise in the invention of the general purpose technologies while others will invest in the 'co-invention' of applications to address particular problems of quality and productivity in one or a few important sectors of their economies" (Foray, Goenega 2013).

The smart specialisation strategies are based on an approach originally suggested by a group of growth and innovation economists (the 'Knowledge for Growth' Expert Group established by the EU Research Commissioner). Later D. Foray developed this concept, with a more precise reference to regional development (Foray 2015). A 'smart specialization strategy' is defined as 'economic transformation agendas integrated and place-based', characterized by five basic elements:

- being focused on certain priorities,

- being built from strengths, competitive advantages and potential of its reference region,

- being referred to a broad concept of innovation, involving the private sector,

- promoting the full involvement of stakeholders through open, participatory processes of 'entrepreneurial discovery', 
- being evidence-based and making central monitoring systems and evaluation also as a learning tool (Foray et al. 2012).

The reference to the term 'specialisation' is quite ambiguous (and perhaps this ambiguity should have been resolved from the start, by avoiding that word). A misunderstanding may emerge from interpreting it as a sort of 'obligation' to focus policies on the strengthening of present industrial / sectorial / technological specialisations. Of course, this is a legitimate political choice, although a highly questionable one in a phase of structural transition. In fact it would be a quite paradoxical combination of neo-liberal economics (as market forces shape specialisations) and picking-the-winners dirigisme.

The strategy - says the Commission - must clearly identify development priorities: 'photocopy strategies' must be avoided and a strategic vision should be developed that is specified on the 'unique' features of the region, through an explicit statement of "where the region would be in the future, what are the main objectives to be achieved and why they are important" (Foray et al. 2012). As Foray himself warned, 'the very word 'specialisation' is prone to misunderstanding and misinterpretation" (Foray 2015, p.15): "smart specialisation is not a planning doctrine that requires a region to specialize in a particular set of industries" (Foray, Goenaga 2013) ${ }^{4}$.

Actually smart specialisation is an invitation not to specialize the economy, but the policies and their objectives. Rather than to achieve a greater level of specialisation of the productive apparatus or to consolidate the current one, the result of a policy inspired by the smart specialisation idea could (and perhaps should) be to promote a well-targeted diversification, based on 'related varieties', i.e. a reduction of sectorial specialisation (Asheim et al. 2001). Also the modernisation of economic activities (e.g. tourism), through the implementation of new technologies, may be a relevant object of the strategy. Likewise, one can well imagine policies that focus, rather than on the existing technological capabilities, on some very significant and distinctive problems of the territories. This would allow developing laboratories of new advanced solutions. Problems / opportunities may be related, e.g., to physical dispersion of human settlements and production or to some major environmental concerns.

Urban settings are often fertile grounds for such developments, as shown by a few interesting connections with the 'smart city' initiatives (Cappellin 2011), e.g. in Apulia. In fact the Commission has pointed out the opportunity to foster new forms of innovation such as open and user-led innovation, service innovation and especially social innovation. Social innovation should have a special role not only because of its impact on welfare, but also as a way to mobilize creativity more widely: in some regions of Southern Italy, such as Apulia and Sicily, interesting experimentations have been developed in this direction. 


\section{An Outward Looking Strategy}

Several aspects of the EU guidelines, defining what smart specialisation is supposed to be, lend themselves to discussion and doubts. Indeed one could argue that some innovative inputs to regional policy making are easier to state than to operationalize.

A good example is provided by the 'outward' orientation, which is expected to characterize the smart specialisation strategies. In the proposal of the European Union the involvement of internal stakeholders and therefore the system of internal connections is necessarily balanced by an equally significant connectivity to the outside, which is a constant and important characterisation of the different stages of the process. In other words, in the era of open innovation and global value chains, the regional innovation system cannot remain 'closed'.

According to the Guide to Research and Innovation Strategies for Smart Specialisation, prepared by the platform of Seville:

$\square$ "A major novelty of the smart specialisation approach is that a region has to make its strategic decisions taking into account its position relative to other regions of Europe, which implies that the RIS3 approach requires looking beyond the regional administrative boundaries. (...) This type of analysis is important because the concept of smart specialisation warns against 'blind' duplication of investments in other European regions. Such blind duplication of efforts could lead to excessive fragmentation, loss of synergy potential, and ultimately could hamper the reach of the critical mass required for success. On the contrary, interregional collaboration should be pursued whenever similarities or complementarities with other regions are detected" (Foray et al. 2012).

Two main assumptions seem to underlie these statements. First, in the world of open innovation and global value chains no serious innovation policy can be effective without the ability to connect local knowledge assets with knowledge existing 'elsewhere' (in other regions, in other countries of Europe and much beyond) (Baldwin 2006; Bellini 2008). The specialisation is 'smart' because it also defines its characteristics and its potential in terms of relative positioning compared to other regions of Europe and takes into account possible co-opetition with them.

Second, having an outward-looking approach allows also the identification of opportunities that may not derive from the present critical mass of innovative activities within the region, but from its present relational assets, which are likely to produce future critical masses. This happens when local actors have built some especially valuable link with outstanding research centres or world-class companies located elsewhere. E.g. a promising 'smart specialisation' is emerging in Palermo (Sicily) in the field of biomedical research, which originates exogenously from a special relationship with the University of Pittsburgh. Similarly, in several regions, we may identify small numbers of companies without autonomous critical mass, but supplying key components or services to some global value chains. In a dynamic perspective these relational assets make those companies much more valuable to the future of the local economy and to its innovation potential than the absolute figures of their size and operations would suggest (Tresca 2013). 
Novelty is not just in the policy approach. In the traditional view of regional systems of innovation, their opening has been often neglected. Some authors have stressed the importance of 'porosity' (Rosenfeld 2005) and of the absorption capacity by systems that are too small to generate their own research inputs. Even when aware of the need to combine, according to a popular metaphor, 'local buzz' and 'global pipelines' (Bathelt et al. 2004), the literature has predominantly focused on the quality and thickness of the relationships within the system. Proximity has been understood primarily in its physical and geographical meaning, following the 'industrial district' ideal type.

The virtualisation of proximity, i.e. the emergence of other kinds of non-spatial proximity (cognitive, organisational, institutional, social etc.), has remained relatively less explored. In fact, the need for a more radical overcoming of the geographical constraints has been recently suggested, in order to integrate local, non-local and virtual networks (Asheim et al. 2011; Asheim et al. 2011; Bellini et al. 2012). This may imply that we consider not only systems defined by geographically wider areas (macro-regional, cross-border, etc.), but also (and perhaps more significantly) that the regional innovation policies should establish their own 'foreign policy', allowing connections with sources of innovation inputs (or with opportunities of application) that are located in other regions (Bellini, Hilpert 2013).

\section{Being 'Outward Looking' in Practice}

The operationalisation of these ideas is actually very complex. The practice of smart specialisation strategies throughout Europe has substantially limited the potential impact of the European guidelines and the paragraphs on the 'external dimension' are normally a marginal addition to the core of the strategy documents. Only a few cases of systematic (but quite concise) discussion exist, e.g. the strategy of Emilia-Romagna identifies a number of Regions in Italy and Europe for each of the selected sectors, both among 'competitive' and 'converging' ones.

The main difficulty lies in the lack of the necessary knowledge. Indeed, almost all the documents propose some consideration of the relative position of the concerned region with respect to others, either on a national or on a European scale. Rankings (in terms of economic performance, $\mathrm{R} \& \mathrm{D}$ expenditures, research infrastructures and human resources etc.) are a powerful communication device to either show one's own strength or give evidence of weaknesses. Relative positioning surely reflects the outcome of the previous path of development. However the obsessive reference to them looks sterile and only justified by the resilient, neo-mercantilist metaphor of the 'competition between territories'.

In many cases these rankings are defined as 'benchmark exercises': it is an inaccurate reference, as little attempts are made to elaborate or contextualize the motivations of the different performance. Furthermore, also the relevance of these rankings in order to identify the candidates for the desired interregional cooperation is not obvious. Often the argument seems to be that cooperation should occur between regions with a similar level of development and similar specialisations. In practice, however, one could argue quite differently, that cooperation makes more sense when there is difference with complementarity. Also in Italy (e.g. in the 
management of science and technology poles) cooperation does not occur between peers, but between advanced and lagging regions.

All documents include some kind of analysis of the regional economy and innovation system, leading to the required 'evidence-based' assessment of the Region's strengths, weaknesses, opportunities and threats. Not all documents seem to include in this SWOT scheme a specific analysis of the positioning of the regional enterprises within the value chains. It may be a matter of data availability, but this is also due to the difficulty of integrating standard economic analysis with less familiar concepts, tools and data belonging to the managerial science. The ability to do so has often be related to the degree of the involvement of company managers and industry experts, allowing for a qualitative and more detailed appreciation of an industry's evolution (as it has been the case in Lombardy, thanks to technology clusters). Unsurprisingly, positioning is also dealt with greater attention in the case of 'micro-regions' (such as Molise).

Knowledge is also limited as far as the relational assets of a Region are concerned. In the perspective of an outward-looking smart specialisation, it would be important to be fully aware of the relational assets that individual actors (such as institutions, companies, universities, etc.) hold and that may take on (at least potentially) a collective relevance. This kind of information ("who cooperates with whom') is normally missing, even when one would expect to have it easily available (e.g. in the case of universities and research centres). In some cases the process of construction of the new strategies is credited to have at least started a discussion in this regard and a preliminary collection of data.

One additional set of missing information concerns the policies of the other regions. In other words, if overlapping has to be avoided and coordination must take place, an exchange of information should take place between the strategymaking processes of the different regions. In many countries this has been a task accomplished by the national governments (that are also required to have their own smart specialisation strategy), with various degrees of commitment and systematisation. E.g. already at early stages, the Spanish government was able to share a synoptic view of the specialisation choices of the autonomous communities. The role of national governments is important also to certify the level of engagement of regions, so that information can be more reliable. In the Italian case a great deal of information has also been shared informally through direct interregional exchanges and in workshops. An important contribution is now given at the European scale by the S3 Platform in Seville, whose specialisation mapping has been turned into an easily accessible, web-based database, named 'Eye@RIS3', including 24 EU Countries and 175 EU Regions with encoded S3 Priorities ${ }^{5}$.

At the same time, some significant and very practical progress could be obtained also in a simpler manner. E.g., it would be useful to internationalize the processes of monitoring and evaluation, providing for peer-reviews, the involvement of experts from other European countries etc. Yet this kind of intention is explicitly mentioned only occasionally.

A more radical move would be the transformation of the many interregional cooperation networks that have been activated by the EU programmes, such as INTERREG. The Region of Lombardy, e.g., has activated the network of the 'Four Engines of Europe' to share a policy approach supporting emerging industries. These networks could evolve from what they are now, i.e. mere opportunities for the exchange of good practices (with limited impact on actual policy making), into 
in-depth peer-review procedures (like in the case of the 'Know-Hub' European network ${ }^{6}$ ) or even in laboratories where common policies could be designed and put in place, fully exploiting the potential to reshape the geography of regional policy making that is implicit in the web of inter-regional relations. But this - with the exception of some celebrated, but also peculiar situations, like the Baltic regions is still to be seen (Bellini, Hilpert 2013).

\section{Conclusions}

As Kevin Morgan rightly pointed out (2013), the choice of the Smart Specialisation simultaneously poses a triple challenge: conceptual, operational and political. Also the issue of the opening of the innovation strategies provides such kind of challenges. Conceptually, it requires to get rid of the old illusion of thinking of local systems as closed ones. Operationally it requires to put in place appropriate assets for internationalisation (Bellini, Bramanti 2008).

But also political stakes are high. On the dusty bookshelves of any scholar of regional development lie dozen of books and papers speculating about the tension between 'global' and 'local' and the impossible mission of dealing with globalisation from the perspective of territorial government. Rather than providing one more rhetorical answer to these worn-out riddles, the smart specialisation process challenges regional governments to give a concrete dimension to the relationship between local development and globalisation, to 'make a difference' in relation to it, by grasping opportunities and not just passively withstanding the consequences. The disappointing results of this endeavour should then be considered with worrying attention.

\section{Bibliography}

Asheim, B.T., Boschma, R., Cooke, P. (2011), Constructing Regional Advantage: Platform Policies Based on Related Variety and Differentiated Knowledge Bases, Regional Studies, vol. 45, n. 7, pp. 893-904.

http://dx.doi.org/10.1080/00343404.2010.543126

Asheim, B.T., Lawton Smith, H., Oughton, C. (2011), Regional innovation Systems: Theory, Empirics and Policy, Regional Studies, vol. 45, n. 7, pp. 875-891.

http://dx.doi.org/10.1080/00343404.2011.596701

Baldwin R. (2006), Globalisation: the Great Unbundling(s), working paper, Prime Minister's Office, Economic Council of Finland, Helsinki.

Bathelt H., Malmberg A., Maskell P. (2004), Clusters and Knowledge: Local buzz, Global Pipelines and the Process of Knowledge Creation, Progress in Human Geography, n. 28, pp. 31-56. http://dx.doi.org/10.1191/0309132504ph469oa

Bellini, N. (2008) Market-Driven Management: the Policy Implications, Symphonya. Emerging Issues in Management (symphonya.unimib.it), n. 1, pp. 34-44 .

http://dx.doi.org/10.4468/2008.1.04bellini

Bellini N., Bramanti A. (2008) Sustainable Glocalisation: A Framework to Analyze the International Relations of Local and Regional Governments, working paper n. 14, Milan: CERTET - Università Bocconi. 
Bellini N., Hilpert U. (eds.) (2013) Europe's Changing Regional Geography. The Impact of Interregional Networks, Routledge, London.

Bellini N., Landabaso M. (2007) Learning about Innovation in Europe's Regional Policy, in Rutten R., Boekema F. (eds.) The Learning Region: Foundations, State-of-the-Art, Future, Edward Elgar, Cheltenham

Bellini N., Teras J., Ylinenpaa Ha. (2012) Science and Technology Parks in the Age of Open Innovation. The Finnish Case, Symphonya. Emerging Issues in Management (symphonya.unimib.it), n. 1, pp. 25-44.

http://dx.doi.org/10.4468/2012.1.03bellini.teras.ylinenpaa

Cappellin, R. (2011) Growth, Consumption and Knowledge Cities, Symphonya. Emerging Issues in Management (symphonya.unimib.it), n. 2, pp. 6-22 .

http://dx.doi.org/10.4468/2011.2.02cappellin

Foray D., Goenega X. (2013), The Goals of Smart Specialisation, S3 Policy Brief Series n 01/2013. Seville: S3 Platform, JRC-IPTS.

Foray D. et al. (2012), Guide to Research and Innovation Strategies for Smart Specialisations (RIS 3), Luxembourg: Publications Office of the European Union.

Foray, D. (2015), Smart Specialisation. Opportunities and challenges for regional innovation policy. Routledge, London.

Morgan K. (2013) The Regional State in the Era of Smart Specialisation, Ekonomiaz, vol. 83, n. 2, pp. 102-125.

Rosenfeld S. (2005) Industry Clusters: Business Choice, Policy Outcome, or Branding Strategy?, Journal of New Business Ideas and Trends, vol. 3, n. 2, pp. 4-13.

Tresca R. (2013) Global Business Networks and the Competitiveness of SMEs, Symphonya. Emerging Issues in Management (symphonya.unimib.it), n. 1, pp. 1-25.

http://dx.doi.org/10.4468/2013.2.05tresca

\section{Notes}

${ }^{1}$ http://s3platform.jrc.ec.europa.eu/home

2 The EU, as of February 2015, has approved only 11 Regional Operational Programmes, including none of the five "convergence" Regions.

${ }^{3}$ A disclaimer is therefore needed. The views expressed here are solely of the author.

${ }^{4}$ Nevertheless, the inertia of semantics has been impressive. Suffice it to refer to the work, made on this occasion by the Italian the National agency for investment promotion and enterprise development, Invitalia. With great methodological care, this study "maps" regional specializations, with the explicit aim to identify those specializations that should be considered more 'robust' (in terms of density of scientific skills, businesses, projects and individuals involved) and therefore should be object of policies of "consolidation". Vertical and horizontal policy coordination, achievement of critical masses and reduction of overlaps are the key concepts in an approach shaped by an explicitly centralist and technocratic view (Invitalia, 2014).

${ }^{5}$ As of February 2015: http://s3platform.jrc.ec.europa.eu/map

${ }^{6}$ http://www.know-hub.eu/ 